Nevertheless, it is interesting to see that the percentage of all persons living at more than two per room in the whole County was 2.55 per cent in 1951 against $13 \cdot 13$ per cent in 1931. Some remarkable re-ranking has occurred among the boroughs in respect of this index. The highest figures are recorded in Paddington, Kensington and St. Pancras, whereas in 1931 the worst conditions were found in Finsbury, Shoreditch and Bethnal Green. In general, the rank correlation between the indexes for the two years is fairly high.

The 1951 Census sought to obtain some wholly new information about housing conditions by asking questions about certain household arrangements. The results for London are presented in tables showing (separately) the percentage of households having exclusive use, sharing or being entirely without piped water, cooking stove, kitchen sink, water eloset and fixed bath. It is not certain that the results of the new inquiry have come up to the expectations of the designers of the census form either on statistical grounds or as sources of unambiguous information about social conditions in different areas: statistically, the value of the results has apparently been somewhat impaired by misunderstanding of the questions on the part of householders; and sociologically, it appears that the results need to be interpreted in the light of other information about household structure. It is, in fact, not nearly as easy as might have been supposed to decide whether relatively extensive sharing of facilities, or even their absence, is an unambiguous sign of poor social conditions in any given area. Some form of factor analysis might be useful in determining significant criteria from this new material. The new tables showing the distribution of heads of households by age, sex and marital condition might prove specially useful in that connexion.

The report contains tables of the percentage of the male population aged seventeen to nineteen in the various boroughs who were engaged in full-time education. They range from 30 per cent in Hampstead to 1 per cent in Shoreditch, and the figures are highly correlated with the percentenge of occupied males in the boroughs who stated their "terminal education age" as being seventeen years or more. The boroughs with high "secondary education" percentages tend slso to be those with high proportions of professional workers and those with relatively high proportions of residents from outside London.

\section{FLAX IN NEW ZEALAND}

$\mathbf{N}^{\mathrm{m}}$

EW ZEALAND has a native plant, Phormium tenax, the leaves of which yield a useful cordage fibre, long known in New Zealand as 'flax' and in commerce as 'New Zealand flax'. This fibre is very different from true flax, the bast fibres from Linum usitatissimum. The confusion of terms was immaterial before 1940, but in that year New Zealand began to grow crops of the true flax, designating it 'linen flax' to differentiate it from the native fibre. Outside New Zealand it is now customary to refer to the native fibre as 'Phormium' fibre or 'New Zealand hemp''hemp' being used as a general term to include all the cordage fibres, while the original hemp fibre from Cannabinus sativa is described as 'true hemp'.

In Great Britain, as a consequence of the cutting off in 1940 of flax supplies from the Continent of
Europe, the Ministry of Supply appesled to New Zealand to grow fifteen thousand acres of flax to help fill the gap. The response was prompt, favourable and energetic. Fortunately, three years before the War the New Zealand Department of Scientific and Industrial Research had arranged for the officers of its Agronomy Division to make investigations of flax growing and processing in association with the Fields Division of the New Zealand Department of Agriculture; and when the crisis came, the officers were able to advise with confidence where and how the flax could be grown, and what yields of fibre and seed might be expected. But no organization was in being; in so novel a situation the difficulties were immense, for the farmers had no knowledge of the flax crop and the engineering firms had no experience of making the processing machinery. The problem was threefold-to establish an industry, to grow the crop and to process it; and the problem was successfully solved, the success being due to splendid team-work.

A report of how all this was done has been prepared by Mr. J. W. Hadfield, formerly director of the Agronomy Division, N.Z. Department of Scientific and Industrial Research*. To start with, a Linen Flax Management Committee was set up, to which Mr. Hadfield was seconded as director of linen flax production. It was arranged that the Department of Agriculture should organize and control all field operations, the arranging of contracts, sowing and harvesting ; that the Marketing Department should handle the export of fibre, tow and seed; and that a Linen Flax Section should be established under the Department of Industries and Commerce to erect mills and carry out all factory operations. The co-operation was secured of the Public Works Department, which undertook the purchase of sites, letting tenders, and supervising the construction of factory buildings and retting tanks. The machinery problem was solved by the help of the Railways Department workshops, which supplied locomotive boilers to the mills and manufactured flax-processing machinery based on European models.

In a few months the new industry was established. The speed with which this co-operative enterprise was developed is reverled by the captions of two photographs in the report: "Instructions to grow flax were received in June 1940. Sowing commenced four months later, and harvesting in January 1941. . . Flax mills were being built while the crops they were to process were growing. The first fibre was delivered from the mills in March 1941".

Part 1 of the report is a plain record of plans and achievements and describes the fascinating details of how the industry was established, without omitting mention of the inevitable disappointments and criticisms. Part 2 describes the application of the general principles of flax growing to the particular conditions of the seventeen areas in the South Island in which the flax was grown. Part 3 describes the processing methods followed at the mills set up in the various growing areas.

It was inevitable that the hasty but successful improvization of flax production in 1940 should be carried out without immediate regard to cost ; more than thirteen thousand acres were actually sown with flax in 1940, and even greater acreages in succeeding years. But after the War, when it became necessary

- Linen Flax Fibre Production In New Zealand. By J. W. Hadfeld. Pp. xviii +125 . (New Zealand : The Linen Flax Corporation of N.Z., and the N.Z. Departments of Agriculture, Industries and Commerce, and Scientific and Industrial Research, 1953.) n.p. 
to effect economies, production was gradually reduced until now only three areas grow the crop. But New Zealand had accomplished what it set out to do ; and it made the very welcome addition of 10,274 tons of highly useful flax to the inadequate British supplies.

The report is not only a permanent record of New Zealand's war effort in flax ; it is also a mine of information, well printed, lavishly illustrated with excellent photographs, invaluable as a guide to flax production, and indispensable to everyone concermed with flax in New Zealand. In short, Mr. Hadfield is to be congratulated on a very fine publication, as are all who had a share in bringing to a successful conclusion the flax enterprise with which it deals.

A. J. TURNER

\section{BOTANICAL HISTORIOGRAPHY}

$\mathrm{D}^{\mathrm{T}}$

R. F. VERDOORN, whose name is well known to botanists, has outlined some of the problems of botanical historiography and has entered the plea that more attention be paid to phytohistory both in its special and more general aspects (Archives Internationales dHistoire des Sciences, 15, 448; 1951 ; published with the assistance of Unesco). He has also indicated an extensive range of projects to which those who are interested in matters botanical, but who are without laboratory facilities for practical research, might well contribute. Some indication of his point of view is given in the following quotations.

"What is botany? Let us not present a definition which is correct according to the philosophers of science, but let us give the very simple, to some of you perhaps annoying, equation :

\section{Botany = Plants + Men."}

"Plants only, we must not forget, do not yield a grain of botany. Yet we will all agree, they are an important part of the equation. Phytohistory, in the widest sense of the word, is the history of the interaction between plants and man's intellectual powers. The history of the vegetable kingdom itself is not phytohistory; depending on our outlook it is historical plant geography, genetics, or paleobotany, but as soon as the human element enters we come into fields, which though they may not all be phytohistory in the strict sense of the word, will nearly always be closely connected with it, as : ethnobotany, the history of cultivated plants, the history of plant names, etc. . . ."

"Phytohistory aims to contribute to these disciplines, but as far as the phytohistorian is concermed, they are borderlands. His real task is to present an integrated picture of the history of the plant sciences as a whole, of their inter-relations with other sciences and then of the history of each of the branches of scientia amabilis. Thereafter, as we cannot consider any science apart from its makers, we come to other aims, such as studies in the history of regional botany, the history of the major schools of botany, the history of botanic gardens (the only botanical institutions of former generations), the history of botanical expeditions, and last, not least, the history of the individuals-botanici typici et atypici-who made the science of plants what it is to-day. . . ."

"If we now agree that the history of the plant sciences has quite a few possibilities, each of them worth further study and research, we may well consider what we can do towards its promotion. These days there are much more than one hundred thousand plant scientists in the world. Some of these contribute by research, others by teaching, again others by organizing work. Many are tied up, a good part of the day, by what we call routine tasks, and others who have time for research do not have the equipment or resources. I believe that there are quite a few hundred good plant scientists amongst us to-day who remain utterly non-productive, but who could well apply their training and energy, reducing the frustration from which they are suffering, to serious work in the history of biology. Let us consider, therefore, in the first place, what can individuals do ?"

Among these things, Dr. Verdoorn lists studies of ethnobotany, the history of cultivated plants and of plant names, of botany and biology as a whole, of individual botanical disciplines, of local and regional botany, of the major schools of botany, of botanic gardens, of botanical expeditions, and "critical biographies of botanists of the past, which yield basic data needed for work in all the other branches of the history of the plant sciences". The importance and value of international co-operation in advancing the aims of phytohistory are also emphasized.

"The first World War destroyed more international co-operation and goodwill than has ever been rebuilt since 1914. And that brings me to another point. In large countries like the U.S.A., England, France and Germany, where mostly national textbooks are used, even graduate students no longer develop a clear concept of the purely international character of science. Yet, a clear realization of the interdependence of scientists is absolutely necessary to train scientists well, to give them positive and progressive ideas about professional ethics, and to counteract the scientist's instinctive inclination towards petty jealousies which only too easily develop into perennial feuds. Any work in the history of a branch of science which gives our students an acquaintance with preceding generations can help immensely in creating a clear understanding of the mutual international dependence of science and scientists and in building positive ideals among the men who, more than any other group in society, will always be the pioneers in building and reconstructing international relations and co-operation."

\section{GENERATION OF RADIO NOISE BY COSMIC SOURCES}

TN a recent paper'1, I concluded that the observed 1 spectrum of general galactic radiation at metre wave-lengths precludes the possibility of a thermal origin by free-free transitions in interstellar gas. The thermal spectrum should have the form $W \propto f^{\varepsilon}$, where $W$ is the observed power at frequency $f$ and $\varepsilon$ is a function of $f$ which is always positive ; the observed value, however, is negative. Another difficulty, pointed out by previous workers, is that accepted estimates of electron densities and tem. peratures would result in a much lower intensity than observed. The same two objections to a thermal origin apply for the major discrete sources; thus the Cygnus source near $100 \mathrm{Mc} . / \mathrm{s}$. has ${ }^{2} \varepsilon \sim-1.2$ and, furthermore, it is unlikely that the observed intensity could be accounted for with reasonable values of electron density and temperature.

Hoyle has recently ${ }^{3}$ suggested $a_{0}$ new process of thermal radio emission from colliding clouds of inter. 